\title{
Using logic to define the Aufbau-Hund-Pauli relation: a guide to teaching orbitals as a single, natural, unfragmented rule-set
}

\author{
Conal Boyce
}

Published online: 15 December 2012

(C) The Author(s) 2012. This article is published with open access at Springerlink.com

\begin{abstract}
The general chemistry curriculum includes a prelude that consumes nearly all of the first semester and occupies the first third of the typical textbook. This necessary prelude to the main event is comparable in scope to precalculus though not broken out as a formal 'prechemistry' course. Atomic orbitals account for much of this preludeto-chemistry. By tradition, orbital theory is conveyed to the student in three disjunct pieces, presented in the following illogical order: the Pauli principle, the Aufbau principle, and Hund's rule. (Often the $n+l$ rule is tossed into the mix as well, though with no fixed place in the scheme). In the early twentieth century, as various researchers announced new insights into the atom at unpredictable intervals, no one could have been faulted for teaching orbitals in such a manner, catch-as-catch-can. A hundred years on, the vestiges of that (presumed) practice look wrong, and are indefensible. In the approach advocated here, orbitals would be taught as a single hierarchical rule-set, with the parts coherently sequenced as Aufbau-Hund-Pauli (and with Madelung's $n+l$ rule rehabilitated as part of Aufbau, no longer a free-floating mnemonic aid only). Logic aside, pragmatism offers its own argument for adopting this scheme: A tighter approach to Aufbau can lighten the 'prechemistry' burden significantly and bring the student that much sooner to chemistry itself.
\end{abstract}

Keywords Aufbau (building-up) · Hund's rule · Pauli principle $\cdot$ Chemistry education · General chemistry curriculum $\cdot$ Madelung's $n+l$ rule

\section{The Aufbau legacy and problem to solve}

In the first-year chemistry curriculum, the teaching of orbital theory is fragmented and incorrectly sequenced. Once understood, the problem is easy enough to start solving, but it contains subtleties and peculiarities (with roots extending back into the 1920s) that make it challenging to articulate. To cover all of its aspects, I present the problem first by way of an

C. Boyce $(\square)$

Century College, Vadnais Heights, MN, USA

e-mail: conalboyce@gmail.com 
analogy, then graphically in Fig. 1 (followed by a proposed solution in Fig. 2). The analogy involves a parent, child, bank and grocery store, as follows:

A child of age five or six happens to be along for the ride 1 day when his father meets with a banker, completes an application, and obtains a credit card. Seizing an opportunity, the parent narrates these events apace, turning them into an impromptu lesson for the child. With this prefatory episode at the bank, we intend an analog to the instructional unit in chemistry that comes just before Aufbau, the one that introduces the quantum numbers



Fig. 1 The Aufbau curriculum as a mobile, with problematic left side 


\begin{tabular}{|c|c|c|c|c|c|c|c|c|c|c|}
\hline \multirow[b]{4}{*}{ Line \# } & \multicolumn{9}{|c|}{ AUFBAU $\rightarrow \mathrm{HUND} \rightarrow \mathrm{PAULI}$} & \multirow{6}{*}{$\begin{array}{l}\text { For now, the 'Be Lazy' } \\
\text { column must serve double- } \\
\text { duty for representing both } \\
\text { Aufbau and Madelung's } n+1 \\
\text { rule from Figure } 1 \text {. In due } \\
\text { course, the latter will be bro- } \\
\text { ken out again, in Figures } 3 \\
\text { and } 4 \text {, for an in-depth look at } \\
\text { its genesis and purport, and its } \\
\text { several geometric versions. }\end{array}$} \\
\hline & \multirow{3}{*}{$1 \mathrm{~s}$} & \multicolumn{4}{|c|}{ Orbital Diagrams } & \multirow{3}{*}{$\begin{array}{c}\text { Is this } \\
\text { configura- } \\
\text { tion } \\
\text { possible? } \\
\text { Yes/No }\end{array}$} & \multicolumn{3}{|c|}{ Yes/No explained via a 3-part rule } & \\
\hline & & $2 \mathrm{~s}$ & & $2 p$ & & & $\begin{array}{c}\mathrm{Be} \\
\text { Lazy }\end{array}$ & $\begin{array}{c}\mathrm{Be} \\
\text { Unseciable }\end{array}$ & $\stackrel{\mathrm{Be}}{ }$ & \\
\hline & & & & $y$ & $z$ & & (always) & (usually) & (when required) & \\
\hline 1 & $\uparrow \downarrow$ & $\uparrow \downarrow$ & $\uparrow \downarrow$ & & & No & C & $\mathrm{V}$ & 0 & \\
\hline 2 & $\uparrow \downarrow$ & & $\uparrow$ & $\downarrow$ & & No & C & v & $\mathrm{O}$ & \\
\hline 3 & $\uparrow \downarrow$ & & $\uparrow$ & $\uparrow$ & & Yes, $\mathrm{C}_{6}$ & C & C & nlá & Note that nearly half the \\
\hline 4 & $\uparrow \downarrow$ & $\uparrow \downarrow$ & $\uparrow \uparrow$ & $\uparrow$ & & No & c & V & V & $\begin{array}{l}\text { entries in our 'Be Distin- } \\
\text { guished' column are ' } \mathrm{n} / \mathrm{a} \text { ' or }\end{array}$ \\
\hline 5 & $\uparrow \downarrow$ & $\uparrow \downarrow$ & $\uparrow$ & $\uparrow$ & $\uparrow$ & Yes, $N_{7}$ & C & C & $n / a$ & 'O'. This points up the hierar- \\
\hline 6 & $\uparrow \downarrow$ & $\uparrow \downarrow$ & $\uparrow \uparrow$ & 凡 & & No & C & V & V & $\begin{array}{l}\text { laziness, then Hund's rule, } \\
\text { then the Pauli principle. } \\
\text { (Hierarchal ves but there is }\end{array}$ \\
\hline 7 & $\uparrow \downarrow$ & $\uparrow 1$ & & $\uparrow$ & & No & C & C & V & $\begin{array}{l}\text { (Hlerarchal, yes, but there Is } \\
\text { a subtlety to note; see } \\
\text { 'Extending the bus seating }\end{array}$ \\
\hline 8 & $\uparrow \downarrow$ & $\uparrow \downarrow$ & $\uparrow \downarrow$ & $\uparrow \downarrow$ & & No & c & V & 0 & analogy' in the text.) \\
\hline 9 & $\uparrow \downarrow$ & $\uparrow \downarrow$ & $\uparrow$ & $\uparrow$ & $\uparrow$ & Yes, $\mathrm{O}_{8}$ & C & C & $c \triangleleft$ & $\begin{array}{l}\text { - In line } 9, \text { the salient points are } \\
\text { [1] oxygen's 8th electron (i.e., }\end{array}$ \\
\hline 10 & $\uparrow \downarrow$ & $\uparrow 1$ & $\uparrow \downarrow$ & $\uparrow \uparrow$ & $\uparrow$ & No & C & C & v & $\begin{array}{l}\text { the second one in the } 2 p_{x} \\
\text { column) has allowed laziness }\end{array}$ \\
\hline 11 & $\uparrow \downarrow$ & $\uparrow \downarrow$ & $\uparrow \downarrow$ & $\uparrow \downarrow$ & $\uparrow$ & Yes, $F_{9}$ & c & C & C & $\begin{array}{l}\text { to trump unsociability (per the } \\
\text { rule-set) and [2] it has }\end{array}$ \\
\hline 12 & $\uparrow \downarrow$ & $\uparrow \downarrow$ & $\uparrow \downarrow$ & $\uparrow \downarrow$ & $\downarrow \downarrow$ & No & C & C & V & $\begin{array}{l}\text { "distinguished" itself with } \\
\text { down-spin, as demanded/pre- }\end{array}$ \\
\hline 13 & $\uparrow \downarrow$ & $\uparrow \downarrow$ & $\uparrow \downarrow$ & $\uparrow \downarrow$ & $\uparrow \downarrow$ & Yes, $\mathrm{Ne}_{10}$ & C & C & C & dicted by the Pauli principle. \\
\hline
\end{tabular}

\section{LEGEND}



Fig. 2 Aufbau-Hund-Pauli as a single hierarchal rule-set for understanding orbitals

$n, l, m_{l}$, and $m_{s}$. Just as $m_{s}$ comes at the conclusion of a coherent narrative, so the credit card appears logically at the conclusion of the multi-step bank visit. Now, with credit card in hand, the parent is inspired to offer the child a second lesson, this time on grocery shopping. But in contrast to the smooth coherence of the bank lesson, the steps for the shopping lesson take on a disjointed aspect, as follows (narrated now in the parent's own voice):

A. Today (Monday) I will take the child to a grocery store and demonstrate how to swipe the card. This demonstration I will perform in a self-service lane; there will be no actual transaction, just the illustration of a card-swipe.

B. Tomorrow (Tuesday) we will make a pretend shopping list at home, then I will throw it away since it won't be real. 
C. On Wednesday, I will take the child to the grocery store a second time. On this occasion, we'll walk the isles together, tossing products into a shopping cart. But we will leave without buying the selected items. Again, it will only be a demonstration, divorced from the context of an actual shopping errand.

After completing steps A, B, C of the above syllabus, the parent congratulates himself on having shown the child, in 3 days' time, all the substituent parts of the activity called grocery shopping. But to an outside observer it will seem that his pedagogy is severely lacking. His assumption seems to be that the child will cleverly, on his/her own, assemble the ad hoc pieces into a coherent whole. But why take such an odd tack? We can't help wondering: Why doesn't the parent do it right with a single quick lesson that is naturally coherent and hierarchal?

In short, to create the desired lesson, why doesn't the parent use an actual shopping list that drives actual purchases followed immediately by a real payment with the credit card? Clearly, the steps labeled A-B-C above can make little sense unless resequenced as B-C-A (meaning: make the list, then shop, then make the payment). By the same token, the tradition-bound textbook sequence of Pauli-Aufbau-Hund should be rearranged so that it too can start to make sense. (As random examples of the problem, see Moore et al. 2005, pp. 292-295 or Kotz et al. 2012, pp. 301-308).

A closer look at the problem: In Fig. 1, four pendants of the "mobile" are numbered vertically to show the conventional sequence, also diagonally to show our proposed resequencing. Thus, Pauli-Aufbau-Hund are numbered 1-2-4 in the vertical series and 4-13 in the diagonal series; it is these two trios of numerals that are analogized by the simpler 'A-B-C' and 'B-C-A' of the child's shopping lesson.

(Viewed this way, my 1-4 numbering scheme seems to have mysterious gaps. It is Madelung's rule that accounts for the gaps. Later we make the case that Madelung's rule is central to Aufbau. We discuss it separately only because it has been divorced from other Aufbau topics by historical circumstance and now requires rehabilitation, not because we believe it to be an ancillary topic. This in turn touches on the question of scope: Ostensibly this paper covers several topics but really there is just the one, symbolized by the top node in Fig. 1. An analogy: Battery design occurs on the interface between physics and chemistry, but whenever a flashlight bulb glows, this event simply is: Now we are back in Nature [in the broadest sense], a place where no one 'knows or cares' about electrochemistry as an engineering specialty that bridges two of our semiarbitrary disciplines.)

But why does the curriculum possess its current form, with Pauli first and Hund last? There are two reasons, both psychologically compelling yet lacking in logic: First, Pauli "happens to be there already" in connection with $m_{s}$ at the tail end of the quantum number presentation; second, it is fun to write a sidebar about such a colorful character, so an author naturally welcomes the first such opportunity that presents itself. All quite understandable, and yet look at the result. Like the $m_{s}$ pendant in Fig. 1, the father's credit card "happens to be there already" at the conclusion of his bank visit, and thus gets introduced unthinkingly and prematurely as "star" of his ill-conceived shopping lesson. The trouble is that Aufbau, when prefaced by the Pauli principle, is a non sequitur. And with logic thus undercut by the textbook author, by the time he/she allows Hund's rule to appear, it will have the flavor of an afterthought, when in fact it is integral to the (true) logic. (For the record, here are two rare examples in which the correct Aufbau-Hund-Pauli sequence is followed: Housecroft and Sharpe (2008, p. 22); Seager and Slabaugh (2011, p. 76). Note, however, that neither of these works is a general chemistry textbook, arguably the place 
where getting it right matters the most. The search goes on for a general chemistry textbook that does it right.)

Where/how does the Madelung $n+l$ rule make its appearance in current practice? Sometimes we find it under Aufbau itself (where it belongs), sometimes near the end of the chapter, cast in the lesser role of electron configuration quiz mnemonic. In Fig. 1, these contrasting cases are represented by the notation ' 3 (or 4)' in the vertical series, which necessitates ' 4 (or 3)' for Hund on the next rung down. In the diagonal series, I elevate Madelung's rule to position 2. (Alternatively, I might have shown it supplanting Aufbau itself, in position 1, but this would have made the overall scheme needlessly lopsided and complex). In these first few pages, our coverage of Madelung is admittedly sparse, but in discussing Figs. 3, 4, 5 below we will remedy that.

Perspective: Let's recall that Aufbau pertains not only to atomic orbitals but also to molecular orbitals (Chang 1991, p. 424), and it recurs as a topic in physical chemistry (Silbey et al. 2005, pp. 377-379), organic chemistry (Bettelheim et al. 2010; McMurry et al. 2010) and inorganic chemistry (Miessler and Tarr 2010, Chapters 2 and 5), now extended to the realm of band theory (Housecroft and Sharpe 2008, pp. 158-160), so it is worthwhile getting it right from the outset.

In Fig. 2, I indicate one of the many ways that Aufbau could be introduced as a coherent, integrated whole, thus showing some consideration for the student. (Depending on the book's size and layout, the student still has between 600 and 900 pages to go at this juncture, with all of chemistry yet to come, and can ill-afford distractions that seem to be 'about physics' but are really just red herrings with no science-education value).

In Fig. 2, we see a proposed rule-set that essentially explains itself by way of thirteen cases (some permitted, others forbidden in Nature) in the general neighborhood of $\mathrm{C}, \mathrm{N}, \mathrm{O}$, $\mathrm{F}, \mathrm{Ne}$ (a semi-arbitrary choice). All thirteen lines exhibit Compliance (C) with the Be Lazy rule. I.e., in occupying subshells, the electrons depicted here have followed the path of least resistance $(1 \mathrm{~s} \rightarrow 2 \mathrm{~s} \rightarrow 2 \mathrm{p}$ ), never performing a quantum leap to a higher-energy subshell such as $3 \mathrm{~s}$.

An electron should "Be Lazy (always)" it says in Fig. 2. But what defines laziness? Madelung's rule, glimpsed at the bottom of Fig. 1, is what defines laziness. (As mentioned, the shape of our narrative dictates that Madeulung's rule be deferred, but conceptually we recognize it as central to Aufbau; this is why).

One could write at length on further nuances whereby Hund's first rule forbids the $2 p$ patterns shown in lines 1, 2, 4, 6 and 8 of Fig. 2, based on energy levels, thus making its own indirect contribution to the definition of laziness (Miessler and Tarr 2010, Chapter 2), but for first-year students it is enough to simply state that lines 1, 4, 6 and 8 violate the rule that says 'Be Unsociable', while line 2 shows a premature application of the Pauli principle, pointless in its attempt to straddle two orbitals. (In line 9, we show the doubling up having occurred arbitrarily in $2 \mathrm{p}_{\mathrm{x}}$. One should point out to the student that this particular doubling could just as well be in $2 \mathrm{p}_{\mathrm{y}}$ or $2 \mathrm{p}_{\mathrm{z}}$ and no rule would be broken).

\section{An easy solution to the $m_{s}$ redundancy (overlap) puzzle}

At some point, the following question arises: "How can I avoid redundancy between [a] the discussion of the spin quantum number, $m_{s}$, in my presentation of $n, l, m_{l}, m_{s}$ and [b] my discussion of the Pauli principle in the ensuing Aufbau-Hund-Pauli presentation that you advocate in your article?" As an indirect answer I offer the following: In the first physics text I open, I find two whole pages devoted to $m_{s}$ (Giancoli 1995, pp. 814-815), 
with no mention of Pauli. Similarly, in Housecroft and Sharpe (2008, p. 15), $m_{s}$ is introduced on its own terms, with no mention of Pauli until seven pages later. As for a direct answer, a solution exists ready-made in the following pair of sentences in Moore et al. (2005, pp. 288-289): "The work of Schrödinger and others found that three quantum numbers $[\ldots]$ are needed to describe the three-dimensional coordinates of an electron's motion in the orbitals in any atom. The need for a fourth quantum number, $m_{s}$, was identified in subsequent work by others". The phrase work by others is apt, given the cast of a dozen plus characters and the zigzagging influences between them all as they groped their way toward the notion of spin and the oxymoron of a "quantum" number with fractional values assigned to it. For the specific contributions to the $m_{s}$ story made by Zeeman, Sommerfeld, Landé, Heisenberg, Pauli, Stoner, Kronig, Uhlenbeck, Goudsmit, Ehrenfest, Lorenz, Einstein, and Thomas (in that order chronologically), see Arabatzis (2006, pp. 200-235), or Pais (1986, pp. 267-280). For the Stern-Gerlach chapter in this story, curiously neglected for many years, one must look elsewhere: See Friedrich and Herschbach (2003), or Sommerfeld (1944) (I: 134-139, II: 142-143).

Finally, let's recall the distinction between [a] spin as a very late and somewhat uncomfortable interpretation of the fourth quantum number and [b] the Pauli principle as an iron-clad but abstract rule, i.e., a formalism only. Cf. Serway and Jewett (2004, p. 945): "PITFALL PREVENTION. Do not be misled; the electron is not physically spinning. It has an intrinsic angular momentum as if it were spinning..." (their emphasis). The same admonition is found in Giancoli (1995, p. 814). Meanwhile, it is not uncommon for chemistry textbooks to assert that electrons do spin. (Cf. Ebbing 1993, p. 292; Masterton and Hurley 2009, p. 141; and Bettelheim et al. 2010, p. 52, all of which even include pictures of spinning balls). From that standpoint, too, the teasing apart of the abstract rule and its physical interpretation is the right thing to do (by contrast with the conventional practice whereby this whole complex business is collapsed to a single point, as it were, labeled 'Pauli').

\section{Extending the bus-seating analogy to accommodate more than Hund's rule alone}

A popular tool for explaining Hund's (first) rule is the bus-seating analogy. When looking at Aufbau-Hund-Pauli together as a single, integrated rule-set or law (as proposed in Fig. 2), can we still make use of the analogy? Yes, if we speak of a double- or triple-decker bus as follows: In line 9 of Fig. 2, the eighth electron says, in effect: "I'd rather not share a seat with you down here on the first level, but I shall as I'm too lazy to climb to the upper deck. I go up there only when all seats on this level are occupied. However, since you and I are doppelgangers, I may not simply sit down parallel to you. Instead, I shall ride antiparallel, standing on my head (feet to the ceiling) to distinguish myself from you and avoid the Pauli Prohibition" [i.e., the Pauli-Verbot, a synonym for Pauli-Prinzip (Sommerfeld 1944, I: 166-167), which some students might find amusing for its connection to colloquial 'verboten' in English].

Thus, with a simple human-behavior analogy we have conveyed to students a rather tricky rule-set, one that involves a three-tier hierarchy with four pieces of logic:

1. Be lazy (i.e., find the lowest possible energy state)

2. Be unsociable...

3. ...but, if it comes down to laziness versus unsociability, let the former trump the latter...

4. ...and, in that case, be distinctive (i.e., invoke the Pauli principle). 
In terms of the examples given in Fig. 2, "down here" in the bus analogy would refer to the $2 \mathrm{p}$ subshell, and the "upper deck" would be the $3 \mathrm{~s}$ or $3 \mathrm{p}$ subshell. If we go along with the conventional wisdom of physics, all electrons are deemed "identical" hence indistinguishable from one another, except in circumstances where a pair might be mutually differentiated by an up-down spin contrast; hence the notion above of a doppelganger pair who may satisfy the Pauli principle if one of them will adopt the inverse of his seat partner's orientation.

\section{Aufbau chronology}

Circa 1921, Bohr and Pauli together developed their basic Atombau (atomic structure) or Aufbauprinzip. In 1925, Pauli published his exclusion principle. Very shortly thereafter, likewise in 1925, Hund published all three of his rules, the first of which finds its way into first-year chemistry. (Sources: Sommerfeld 1944, I: 168-169; Arabatzis 2006, pp. 207 n.18 and 215 n.42; Miessler and Tarr 2010, Ch. 2, where the following are cited: Pauli, Z. Physik 1925, 31, 765; Hund, Z. Physik 1925, 33, 345. Regarding Hund's third rule, see Kutzelnigg 1996, pp. 579-580 and 585, where he cites Z. Physik 1925, 33, 855). Thus, for all practical purposes, the publication of Hund's three rules and the Pauli principle were contemporaneous. In conflict with the above facts, however, there exists the myth of Hund's rule appearing 'around 1927': That phrase is found in Ebbing 1993, for example, and in the wikipedia article on 'Hund's rule' (accessed 3 December 2012). Somehow, this erroneous 2-year separation of Hund from Pauli is probably related to the practice of treating Hund's rule(s) as an afterthought, although one can imagine the cause-effect arrow going either way. (I.e., if one already has accepted the notion of Hund's rule as secondary or tertiary, then one has no motivation for questioning 'about 1927'; conversely, if one has internalized 'about 1927' already, then one is primed to accept Hund as an afterthought; but in either case one will have erred). In Kutzelnigg (1996, p. 580), a complaint similar to mine is registered: "Despite their popularity, Hund's rules are mentioned almost by the way in textbooks on the electronic structures and spectra of atoms"; my italics. Other questions of chronology: With Janet and Madelung there is a question of priority, addressed in the next section.

\section{Toward rehabilitation of Madelung's rule as an integral part of Aufbau}

Figure 3a has long been the prevalent textbook version of Madelung's $n+l$ rule. But given all the variants that exist (of which Fig. 3b-f are only a sampling), one might infer that students and/or instructors have experienced some frustration with Fig. 3a. What could be the trouble?

The trouble is that Fig. 3a contains an internal contradiction: Its $l$-scale increments from left to right, but its arrows point from lower-right to upper-left, running against the grain (and for no good reason). The dissonance is relieved somewhat by Fig. 3b, where a modest step is taken in the direction of Fig. 3d, but internally Fig. 3b carries with it the same contradiction that exists in Fig. 3a. Like Fig. 3b, the Fig. 3c variant is trying to allow a notional "gravity" to take over, but with an $l$-scale that now climbs against the grain, one type of dissonance has been traded for another.

Only Fig. 3d succeeds in harmonizing its $l$-scale and arrows, so that everything now flows as if "under the influence of gravity". Everything except the retrograde transitions, 


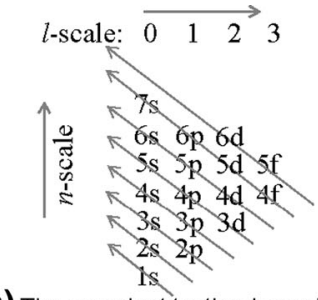

(a) The prevalent textbook version After Kotz et al. 2012, p. 303, Denniston et al. 2008, p. 67, Moore et al. 2005, p. 300



(d) Hybrid of (b) \& (c), with a staircased $n$-scale to make a better "gravity" version



(b)

Like (a), but flipped vertically to accord (somewhat) with "gravity" After Chang 1991, p. 289

l-scale: $3 \overleftarrow{2} 10$



(e) The Charles Janet version After Winter 1994, p. 25



(c) Like (b), but rotated After Hill \& Kolb, 1998 , p. 66



(f) After Masterton \& Hurley 2009, p. 144 Cf. McMurry et al. 2010, Chapter 3

Fig. 3 The $n+l$ rule in six of its modern representations

that is: Here we can finally see which parts of the array are genuinely anomalous (numerically "backward" as from 5s to 4d) and which flow smoothly in Nature. (The first four retrograde cases I've flagged with circles; the not-so-obvious ones I've flagged with dashed-line circles). To the extent that these half-dozen anomalies cannot be wrung out of the array, even in Fig. 3d, Nature exhibits subtlety, yes, but nothing like the dissonance needlessly invoked by Fig. 3a.

At first sight, the Janet scheme (Fig. 3e), which is usually shown without arrows (e.g., in Winter 1994, p. 25) may appear to be the long-sought ideal. Doesn't it partake of a simplicity that mocks the tortuous schemes of Fig. 3a-d? No. With the arrows added, it turns out to possess a dissonance even more harsh than that of Fig. 3a. Here we have leftto-right arrows placed in $180^{\circ}$ opposition to the $l$-scale, which now increments right-to-left.

In the literature, Fig. 3a (or any of its many permutations) is referred to as Madelung's rule (e.g., in Scerri 2011, pp. 91, 100; in Bent 2006, p. 62). Now Fig. 3a is readily mapped to Madelung (1936, p. 360), but it bears not the slightest resemblance to the original formulation, which was tabular, not geometric. (For an excerpt of the real thing, see Fig. 4).

As for textbooks, the practice there is to label Fig. 3a (or any of its variants) as the Order of Subshell Filling, or words to that effect (i.e., the diagram simply appears, without its formal name and with no source indicated). Sometimes, noting an attribution is more than just a matter of decorum, though. The $n+l$ rule is a case in point. With its attribution removed, its genesis too is lost, and in its untethered state it undergoes a downward spiral, as follows: First, the student is left to assume that the rule's raison d'être is to help him/her answer electron configuration questions. Too many years of familiarity with the Order-ofSubshell-Filling diagram may in turn provoke an instructor to disparage it as "just 


\begin{tabular}{|c|c|c|c|c|c|}
\hline \multicolumn{5}{|c|}{$\begin{array}{l}\text { The } n+l \text { rule } \\
\text { as given in Madelung, } 1936, \text { p. } 360 \text { (excerpt) }\end{array}$} & \multirow{2}{*}{$\begin{array}{c}\text { Janet's } \\
1929 \text { version } \\
\text { (after Winter, } \\
1994 \text {, p. } 25 \text { ) }\end{array}$} \\
\hline & $n+l$ & $n$ & & here $0,1,2,3=s, p, d, f)$ & \\
\hline $\mathrm{H}$ & 1 & 1 & 0 & & \\
\hline $\mathrm{He}$ & 1 & 1 & 0 & & \\
\hline Li & 2 & 2 & 0 & & \\
\hline $\mathrm{Be}$ & 2 & 2 & 0 & & \\
\hline B & 3 & 2 & 1 & & \\
\hline C & 3 & 2 & 1 & & \\
\hline $\mathrm{N}$ & 3 & 2 & 1 & & \\
\hline 0 & 3 & 2 & 1 & & $\uparrow$ \\
\hline$F$ & 3 & 2 & 1 & & \\
\hline $\mathrm{Ne}$ & 3 & 2 & 1 & & \\
\hline $\mathrm{Na}$ & 3 & 3 & 0 & & \\
\hline $\mathrm{Mg}$ & 3 & 3 & 0 & & \\
\hline Al & 4 & 3 & 1 & & \\
\hline $\mathrm{Si}$ & 4 & 3 & 1 & & \\
\hline $\mathrm{P}$ & 4 & 3 & 1 & & \\
\hline$S$ & 4 & 3 & 1 & & $\uparrow$ \\
\hline $\mathrm{Cl}$ & 4 & 3 & 1 & & \\
\hline $\operatorname{Ar}$ & 4 & 3 & 1 & & \\
\hline $\mathrm{K}$ & 4 & 4 & 0 & $\zeta$ & \\
\hline $\mathrm{Ca}$ & 4 & 4 & 0 & & \\
\hline $\begin{array}{l}\text { Sc } \\
\vdots \\
\text { u }\end{array}$ & $\dot{5}$ & $\begin{array}{l}3 \\
: \\
5\end{array}$ & : & & $\begin{array}{r}\longrightarrow 3 d 4 p 5 s \\
4 d 5 p 6 s \\
4 f 5 d 6 p 7 s \\
\longrightarrow 5 f 6 d 7 p 8 s\end{array}$ \\
\hline
\end{tabular}

Fig. 4 Comparison of the $n+l$ rule per Madelung and per Janet

numerology". For example, Ludwig (1992) reacts to it as if it were only a test-takers' crutch built around the periodic table and not a distinguished scientist's insight into the periodic table. Accordingly, Ludwig advocates abandoning the $n+l$ rule and focusing instead on the periodic table, as if to say the former is meaningless and latter real. We might sympathize with Ludwig's "purist" motivation, but his remedy is extreme and not supportable: Note how the $n+l$ rule and periodic table are represented together in Fig. 5, each a legitimate contributor to the one picture that is now "in Nature", no longer subject to his critique. Finally, because it is perceived by student and textbook author alike as onlya-mnemonic, the rule floats freely in textbooks, having no fixed adobe (as symbolized by the 'or 4' in Fig. 1). For example, in Denniston et al. (2008, p. 67) and in Kotz et al. (2012, p. 303), it is placed inside the Aufbau section where it belongs; in Moore et al. (2005, p. 300) and in McMurry et al. (2010, Ch. 3), it occurs much later, as an adjunct to electron configurations.

Suppose no such mnemonic is included in the atomic orbitals chapter. Then the author falls back on a kind of brute-force indoctrination, piece by painful piece, culminating in an 







enhanced periodic table that has an electron configuration jammed into every cell in extremely small font. See Zumdahl (1989, p. 296), and Ebbing (1993, p. 300), for examples of this style.

Concluding remarks on Fig. 3: For contemplative, philosophical appeal, Fig. 3d strikes me as the clear winner. However, it would seem a dubious choice for the student in search of a mnemonic. Figure $3 \mathrm{f}$ is refreshing for having bucked the trend outright, and like Fig. 3d it even possesses some philosophical appeal. But as a mnemonic I don't see Fig. 3f helping the student much. For use as a mnemonic, Fig. $3 \mathrm{~b}$ might be best, even with the defect noted earlier. In summary, I think both aspects of the rule-as an integral part of Aufbau and as a mnemonic for the student-are equally important. But its diverse graphical representations are not freely interchangeable for all audiences.

On the left side of Fig. 4 I have reproduced a portion of Madelung's 'Catalog of Electrons', the distilled (graphical) essence of which is known to us today as 'Madelung's rule'. (Here I show columns 2 through 5 only. The actual table contains six additional columns. I curtail the list at Sc, which is the first place that $n$ goes retrograde, whereas the original table continues on through $\mathrm{U}$, stopping only when it reaches a blank row for $\mathrm{Z}=103$. I think it is worthwhile reproducing his table, even in this abridged form, because it has fallen into obscurity). And what was Sommerfeld thinking when he summed those two quantum numbers to create his $n+l$ column? Here is a clue: "The catalog [i.e., the table that occupies all of p. 360] is the depiction of an empirical rule" (Der Katalog ist die Darstellungsform einer empirischen Regel); Madelung (1936), p. 359, his italics.

On the right side of Fig. 4, I show Janet's 1929 version (in its entirety). This is the same as Fig. 3e, but with the first four rows now vertically spaced out, to force their alignment with the corresponding segments of Madelung's formulation, marked out here by curly braces. One is struck by the fact that both Madelung and Janet use an orthogonal (square) presentation: i.e., neither of them indulges in the slanting, zigzagging or vortexing that we've come to regard as normal in present-day representations of the rule. Also, Madelung's rule appeared 7 years later than Janet's, at the back of the third edition of his Die Mathematischen Hilfsmittel des Physikers, and then only as a slender appendix called 'Atomic Structure: Catalog of Electrons' (Madelung 1936, pp. 359-360). But the appearance of the Janet version is deceptive; see earlier remarks about the maximal dissonance of Fig. 3e. Given that weakness, I think a claim today about its publication priority relative to Madelung would have no traction. (A better case could be made for AlexandreÉmile Béguyer De Chancourtois as the one who discovered periodicity 7 years prior to Mendeleev; see Scerri 2011, pp. 43-45, and Emsley 2000, pp. 265-266). By contrast with the dubious status of Janet's rule, the reputation of his (1929) Left-Step Periodic Table (hereafter LSPT) has been elevated recently by attention from Eric Scerri: Near the conclusion of his 2011 book, Scerri takes a close look at the LSPT (pp. 125-131), followed by a comparison of the triad-maximizing periodic table (pp. 131-137). In his 2007 book, The Periodic Table, Scerri felt strongly enough about the LSPT to advocate its general adoption, per Kaji (2007).

As noted above, Madelung's rule is a conspicuously late entry (1936) in the Aufbau publication sequence, and this may partially explain, though not excuse, its treatment nowadays as a (mere) student mnemonic. Eventually one would hope to see it rehabilitated as the main event in Aufbau itself (without ever denying its value as an electron configuration mnemonic, too).

When it comes to Fig. 5, I am no longer in my "advocacy" mode; I admit that Fig. 5 would probably have limited appeal in the classroom. I include it only for the sake of following through on my claim in Fig. 1 (top node callout) and elsewhere that this is all 
"one topic". (The Fig. 5 callouts in a colored font are a random sampling of electron configurations, to suggest how they could be 'read off', generally, from the table itself). Others who take a similar approach to the problem of integrating electron configurations with the periodic table are Barber and Taylor (1953), on the flyleaf; Masterton and Hurley (2009, p. 146); and Silbey et al. (2005, p. 379). With Fig. 5, my intention is to demonstrate how Fig. 3d, far from being (just) a mnemonic tool, actually is the periodic table and is Aufbau, in a sense.

Now that we have moved beyond the admittedly myopic view of individual rules as examined earlier, it would be appropriate to consider the viewpoint of Tsimmerman (2012). In effect, he poses the following question: Why, after all, should any of this be reducible to two-dimensional tables, given that Nature has three or four or perhaps eleven dimensions to play with? In particular, why should we expect that one of our simple flat tables might be able to convey the distilled essence of the whole shebang? As for the right side of ' $n+l=$ ?', his proposal is $n+l=n_{\max }$ " where ' $n_{\max }$ ' is the maximum value of the primary quantum number ' $n$ ' for each triangular layer of [atoms] of the growing tetrahedral stack defined as ' $n+l$ '." After some years on the fringe, it seems that his tetrahedral model is starting to be discussed seriously in the academic world lately.

\section{Broader curriculum issues}

Our reassessment of Aufbau assumed a particular context: the first semester of a collegelevel chemistry class. For convenience, let's assign the tag 'Chem 1001' to that piece of the curriculum and assign the tag 'Chem 1002' to the class that closes out the first year. Into Chem 1001 is loaded a huge prechemistry infrastructure with Aufbau accounting for, say, one fifth of the total. By 'prechemistry infrastructure' I refer to the following: scientific notation, SI units and significant figures as a set of rules to learn, not yet as a set of tools; the laboratory as a "foreign country" to learn about, not yet a place for carrying out procedures; the periodic table as a collection of symbols-to-learn, not yet as the Rosetta stone for reactivity; quantum mechanics rudiments including the Aufbau-related minitopics and electron configurations as a kind of foreign language alphabet, not yet as an analytical tool; stoichiometric calculation as a kind of exotic algebra, not yet as a laboratory technique; and so on. In terms of class work, roughly one half of first-year chemistry is devoted to this infrastructure; as for textbook space, roughly the first third of the typical volume is devoted to it. (Thus, Chem 1001 bears a strong resemblance to precalculus, although it has yet to be broken out as a distinct "industry" in the manner of precalculus, which has a separate faculty-textbook-subculture in the U.S. at least.)

Not only does the infrastructure burden of Chem 1001 cause a general postponement of actual chemistry topics to Chem 1002, but many students regard Chem 1001 and Chem 1002 together as a mere stepping stone to the higher chemistries, so to speak. On this view, the raison d'être of general chemistry in its entirety is the role it plays as 'pre-organic', i.e., it is merely the gateway to organic and biochemistry. Meanwhile, general chemistry (the underdog toward which I admit a strong bias) is in constant danger of being edged off the table by the combined pressure of the infrastructure topics that dominate Chem 1001 and the rush-to-organic mentality that pervades Chem 1002. An example of the edging-off problem: From textbooks, it is clear that molecular orbital theory is intended to appear somewhere in the first-year curriculum, but in terms of actual coursework it sometimes gets short shrift, appearing as a full-fledged unit of instruction in neither Chem 1001 nor Chem 1002. 
And where might so-called inorganic chemistry fit into the landscape?

If organic chemistry is defined as the chemistry of compounds of carbon, primarily those containing hydrogen or halogens plus other elements, inorganic chemistry can be described broadly as the chemistry of "everything else." This includes all the remaining elements in the periodic table, as well as carbon, which plays a major role in many inorganic compounds. Organometallic chemistry, a very large and rapidly growing field, bridges [the two] areas by considering compounds containing direct metal-carbon bonds. As can be imagined, the inorganic realm is extremely broad, providing essentially limitless areas for investigation. - Miessler and Tarr, p. 1

Here I have quoted the opening paragraph in Miessler and Tarr (2010) in full. At first glance, it seems a concise and satisfactory answer to the question: "What is inorganic chemistry?" I take issue, however, with the phrase "everything else". I find it too pat, with its intimation of a neat and orderly division-of-labor between organic and inorganic (which in any event is gradually being recognized as a false dichotomy). In my view, inorganic chemistry is emphatically not the place where "everything else" is handled; rather, it is the place where everything-period-is handled, as one recovers from the "edging out" described earlier and recaptures one's vision of general chemistry as the field driven by the entire periodic table. In other words, it is the place where general chemistry rises, phoenixlike, under a new name.

Acknowledgments For an introduction to the writings of Arabatzis, and for insights into the nature of the 'Chem 1001/1002' contrast, I am indebted to Alison Boyce.

Open Access This article is distributed under the terms of the Creative Commons Attribution License which permits any use, distribution, and reproduction in any medium, provided the original author(s) and the source are credited.

\section{References}

Arabatzis, T.: Representing Electrons. University of Chicago Press, Chicago (2006)

Barber, H., Taylor, T.I.: Semimicro Qualitative Analysis. Revision of 1942 1st edn (1953)

Bent, H.: New Ideas in Chemistry from Fresh Energy for the Periodic Law. AuthorHouse (2006)

Bettelheim, F.A., Brown, W.H., Campbell, M.K., Farrell, S.O.: Introduction to General, Organic, and Biochemistry, 9th edn. Brooks/Cole-Thomson Learning, Belmont, CA (2010)

Chang, R.: Chemistry, 4th edn. McGraw-Hill, Dubuque, IA (1991)

Denniston, K., Topping, J., Caret, R.: General, Organic, and Biochemistry, 6th edn. McGraw-Hill, Dubuque, IA (2008)

Ebbing, D.D.: General Chemistry, 4th edn. Houghton Mifflin Company, Boston, MA (1993)

Emsley, J.: The Elements, 3rd edn (1998) with corrections (2000)

Friedrich, B., Herschbach, D.: Stern and Gerlach: how a bad cigar helped reorient atomic physics. Phys. Today 56, 53-59 (2003)

Giancoli, D.C: Physics, 4th edn. Prentice Hall, Upper Saddle River, NJ (1995)

Hill, J.W., Kolb, D.K.: Chemistry for Changing Times, 8th edn. Prentice-Hall, Upper Saddle River, NJ (1998)

Housecroft, C., Sharpe, A.G.: Inorganic Chemistry, 3rd edn. Pearson Prentice Hall, Harlow (2008)

Kaji, M.: Book review, Eric Scerri, The Periodic Table: Its Story and Significance (2007). HYLE Int. J. Philos. Chem. 13(2), 119-121 (2007)

Kotz, J.C., Treichel, P.M., Townsend, J.R.: Chemistry and Chemical Reactivity, 8th edn. Brooks/ColeThomson Learning, London (2012)

Kutzelnigg, W.: Friedrich Hund and Chemistry. Angew. Chem. Int. Ed. Engl. 35, 573-586 (1996)

Ludwig, O.G.: The best Aufbau mnemonic: the periodic table. J. Chem. Educ. 69, 430 (1992)

Madelung, E.: Die Mathematischen Hilfsmittel des Physikers, 3rd German edn. Springer, Berlin (1936) 
Masterton, W.L., Hurley, C.N.: Chemistry: Principles and Reactions, 6th edn. Brooks/Cole-Cengage Learning, Belmont, CA (2009)

McMurry, J., Castellion, M.E., Ballantine, D.S.: Fundamentals of General, Organic, and Biological Chemistry, 7th edn. Prentice Hall, Upper Saddle River, NJ (2010)

Miessler, G.L., Tarr, D.A.: Inorganic Chemistry, 4th edn. Prentice Hall, Upper Saddle River, NJ (2010)

Moore, J.W., Stanitski, C.L., Jurs, P.C.: Chemistry: The Molecular Science, 2nd edn. Brooks/Cole-Thomson Learning, Belmont, CA (2005)

Pais, A.: Inward Bound. Oxford University Press, Oxford (1986)

Scerri, E.R.: The Periodic Table: A Very Short Introduction. Oxford University Press, Oxford (2011)

Seager, S.L., Slabaugh, M.R.: Introductory Chemistry for Today, 7th edn. Brooks/Cole-Cengage Learning, Belmont, CA (2011)

Serway, R. A., Jewett, J.W.: Physics for Scientists and Engineers, 6th edn. Brooks/Cole-Cengage Learning, Belmont, CA (2004)

Silbey, R.J., Alberty, R.A., Bawendi, M.G.: Physical Chemistry, 4th edn. Wiley, Hoboken, NJ (2005)

Sommerfeld, A.: Atombau und Spektrallinien, 6th edn. Friedr. Vieweg \& Sohn, Braunschweig (1944)

Tsimmerman, V.: On [the] Tetrahedral Character of the Periodic System. http://www.perfectperiodictable. com (2012). Accessed 3 Dec 2012

Winter, M.: Chemical Bonding. Oxford University Press, Oxford (1994)

Zumdahl, S.S.: Chemistry, 2nd edn. D.C. Heath and Company, Lexington, MA (1989) 